\title{
Enunciación
}

http://revistas.udistrital.edu.co/ojs/index.php/enunc

\section{Por una escritura situada en el ámbito de la investigación social ${ }^{*}$}

\author{
For a Situated Writing in the Field of Social Research
}

\author{
Carlos Eduardo Valenzuela Echeverri ${ }^{1}$
}

Para citar este artículo: Valenzuela, C. E. (2014). Por una escritura situada en el ámbito de la investigación social. Enunciación, 19(1), 107-115.

Recibido: 10-abril-2014 / Aprobado: 31-julio-2014

\section{Resumen}

¿Cuán desprovista de sujeto ha de estar la palabra de quien escribe hoy por hoy en el ámbito de la investigación social? Lo suficiente, diríamos otrora desde una ortodoxia epistémica duramente enjuiciada hoy, so pena de perder el calificativo de investigador, el cual parece hacer de quien 'escribe' un verdadero escribano al servicio de la ciencia. Sin embargo, son ya otras voces, otras posturas, otros "decires" que se erigen en el presente para hablarnos desde ángulos distintos acerca de la escritura en la investigación social, tema sobre el que trata este artículo.

Palabras clave: autor, ciencia, investigación social, posmodernidad

\begin{abstract}
How lacking of subject is nowadays the word of those who write in the field of social research? Just enough, we might once say from an epistemic orthodoxy way in which is so severely judged today, by fear of losing the label of researcher, which seems to make of the "writer" a real scribe at the service of science. However, there are now other voices, other attitudes, other "sayings" which are currently raising up to speak from different views about writing in social research, a subject on which this article will be mainly dealing with.
\end{abstract}

Keywords: author, science, social research, postmodernism

\footnotetext{
*sta tesis de maestría, en la que se basó el artículo, fue publicada por la UPN en 2013 con el título de Escritura e investigación social: más allá de la presencia. Consideraciones derridianas en torno al problema de la representación en ciencias sociales.

1 Licenciado en psicología y pedagogía; especialista en comunicación-educación y magíster en estudios sociales de la Universidad Pedagógica Nacional
} UPN, Bogotá, Colombia. Correo electrónico: duardoco@yahoo.com 


\section{INTRODUCCIÓN}

Atendiendo a la amable invitación de la editora del presente número de la revista Enunciación, dedicado a la lectura y la escritura, el objeto de este artículo radica en compartir justamente algunas reflexiones respecto de la escritura en nuestro quehacer investigativo, tema que derivó de la tesis de maestría titulada El lugar de la escritura en la investigación social: una mirada a "Hoguera de las ilusiones de Arturo Alape" (2011).

Dicha investigación, cuya metodología fundamenté en la hermenéutica de Paul Ricœur (2002), se trazó como propósito analizar desde corrientes posestructuralistas el lugar epistémico que, como investigadores sociales, solemos endilgarle a la escritura en nuestro trabajo. De fondo, el problema que enfrentó la investigación fue aquel asociado al declive de la representación en ciencias sociales. De allí su asiento en autores posmodernos como Derrida o Locke, en quienes basé buena parte de las elaboraciones teóricas que me permitieron avanzar en el análisis hermenéutico de una escritura en particular: la de Alape, y su despliegue en el terreno de la investigación social.

Así pues, el artículo lo desarrollo a través de tres gruesos apartados: en el primero, avanzo en la pregunta por el carácter situado de lo escrito; en el segundo, rastreo las implicancias metodológico-reflexivas de tal perspectiva en el ámbito propio de las ciencias sociales; $y$, en el tercero y último, pongo de relieve la naturaleza constitutiva de la escritura situada, leída a través de la frontera: escritura literaria - escritura científica.

\section{Consideraciones a propósito de una escritura situada}

Diversas tendencias reivindican hoy por hoy el papel de lo subjetivo, lo emocional y lo estético en la escritura científica. La antropología posmoderna, por ejemplo, a través de las etnografías experimentales, viene asestándole duros golpes a la autoridad del investigador y su escritura; una escritura que, distintiva en el pasado de un estructuralismo objetivo cuya mirada omni-abarcante de mundo buscaba hacer de este una totalidad explicable, ahora se asocia (Locke, 1997) a la del novelista quien, a contracorriente de un monologismo ideológico, decide hablarnos del mundo a través de sus propios héroes y no mediante la univocidad de una idea monolítica que no reconoce punto de vista, posición o sujeto alguno (Bajtín, 1986), constituyendo su relato en un objeto polifónico.

Así, en el marco de estas problematizaciones, encontramos distintos autores que ponderan, como Joel Feliu (2007) y David Locke (1997), otras formas literarias de escribir en investigación "que cuestionen los efectos de poder habituales, sin perder de vista el objetivo final de la producción de conocimiento, que es la reflexión de la sociedad sobre sí misma" (Feliu, 2007, p.262). Al fin y al cabo, no importa la ortodoxia con la que suele leerse la escritura científica; esta obedece también a un sentido específico que por lo general la ciencia soslaya. De hecho, en la medida en que se ha creído de forma ingenua que la escritura en ciencia no es retórica, sino atestamiento de lo que la realidad es, no se ha reparado en advertir sus formas particulares de expresión, formas que se entrelazan de manera consistente al contenido, siendo muchas veces indiscernible su relación:

Uno no puede escribir de cualquier manera en un artículo científico, es decir, no puede salirse de la forma literaria que tiene asignada, y si lo hace, asume ciertos riesgos, como el de la pérdida de credibilidad para empezar. Eso lleva a pensar que la credibilidad de un artículo, junto con otras características, se pone en juego en el momento de dar forma al contenido. Y es más, nos puede hacer pensar que precisamente estas características científicas reposan más en la forma que en el contenido, es decir, en adscribirse correctamente en el género adecuado. (Feliu, 2007, p.264) 
De otro lado, está el asunto del autor. Y es justamente aquí donde más se hace evidente el cuestionamiento hecho por la antropología posmoderna al tema de la autoridad científica. En efecto, el problema del autor en materia de ciencia parece resolverse con facilidad para esta, por cuanto no hay más autor que la autoridad científica, es decir, el proceder mismo de la ciencia que, al hablar, no interpreta, dice lo que es, pues dicho decir no es más que la 'verdad', no elucubración subjetiva: "Los científicos, por encima de todo, mantienen que sus representaciones no son ficticias, como puedan serlo francamente las representaciones literarias; aquellas comunican lo que, de hecho, los científicos creen que ha sucedido realmente" (Locke, 1997, p.45).

En tal medida, escribir para los científicos tradicionales equivale a señalar lo que la realidad es; son realistas por definición, no consideran que puedan no serlo, "ellos creen que están consignando, representando, lo que realmente sucedió, y que esa representación debe ser, a primera vista, realista" (Locke, 1997, p.47). De ahí que no se preocupen por la cuestión del autor, su único propósito es hallar y representar, del modo más fiel posible, lo que hay realmente en la naturaleza, lógica subsidiaria como es obvio de la metafísica de la presencia, ${ }^{2}$ cuyo afán de representatividad parece invadir a los científicos ortodoxos.

Ahora, si la cuestión del frenesí por la representación, como resulta ostensible, fue heredada, de seguro esta debió traer consigo la desconfianza por la escritura, signo imperfecto de aquello que se quiere decir; de allí la amenaza constante que se cierne sobre los científicos de perder la objetividad al representar por medio de la escritura la verdad. Si de entrada la escritura es, por principio, imperfecta, subjetivar además lo que se dice no

2 De acuerdo con Derrida, el afán de Occidente por someter la realidad al escrutinio de una norma ideal, principio absoluto o valor general que la explique, hace de su cultura una cultura devota de la metafísica de la presencia, es decir, fiel a una metafísica entendida "como escritura teórica organizada en torno a un centro privilegiado: la presencia" (1989, p.24). contribuiría en nada al cometido representativista de la ciencia.

En consecuencia, de acuerdo con esta lógica esencialista que nos habla de una ciencia reificada, no es el sujeto quien escribe, es la autoridad de la ciencia, equivalente al método, las instituciones y las disciplinas, las que lo hacen. Por lo tanto, la escritura se hace aquí mero instrumento representacional del discurso de la ciencia, al que se adscribe el científico al participar de "sus autoafirmadas máxima neutralidad y objetividad, honestidad y desinterés personal, de su retórica del conocer por el conocer" (Feliu, 2007, pp.264265). Tal entrega del científico tradicional al determinismo de la ciencia lleva a que la escritura misma se invisibilice, pues:

El lenguaje, para la ciencia, no es más que un instrumento que interesa que se vuelva lo más transparente, lo más neutro posible, al servicio de la materia científica (operaciones, hipótesis, resultados) que se supone existe fuera de él y que le precede: por una parte, y en principio, están los contenidos del mensaje científico, que lo son todo, $y$, por otra parte, a continuación está la forma verbal que se encarga de expresar tales contenidos, y que no es nada. (Barthes, 1987, p.14)

El científico deja así de reparar en la escritura en razón de la fe ciega que tiene en la ilusión de poder explorar la realidad directamente, que lo es todo, sin mediación del lenguaje, premisa básica de la teoría científica de la representación que autores como Locke (1997) y Feliu (2007) atacan, sumándose, mutatis mutandis, a lo que Derrida (1989) combate sin cuartel: pensar que existe una realidad plena y significativa (presencia) de la que es posible dar cuenta a través del signo:

No puede concebirse que el mundo complejo de la ciencia moderna pudiera ser directamente accesible para la mente no mediada por el lenguaje y la matemática. En último término, defender que el científico explora de alguna manera el mundo real 
(presencia) directamente, sin la mediación del lenguaje, y que así representa, refleja o traduce a lenguaje esta imagen del mundo, es impensable. Pero esto es justamente lo que afirma la teoría científica de la representación. (Locke, 1997, p.51)

Este viraje, inscrito en lo que propiamente se ha dado en Ilamar el giro lingüístico, de acuerdo con el cual "no se da conocimiento sin lenguaje $y$, por tanto, ni racionalidad ni ciencia sin forma lingüística" (Bermejo, 2008, p.52), pone de relieve el carácter situado de la escritura científica. En otras palabras, "el lenguaje no describe meramente lo que el científico hace, sino que en realidad contribuye a determinarlo" (Bermejo, 2008, p.58). Esta valoración de cuño posmoderno ${ }^{3}$ resulta ser la piedra angular del planteamiento sobre el que autores como Locke (1997) y Feliu (2007) se apoyan para hablarnos acerca de las implicancias de una escritura situada en el ámbito metodológico propio de las ciencias sociales. Una escritura que refrenda el interés por residir en lo que escribe, a diferencia del paradigma occidental de la escritura científica que la hace refractaria al sujeto, excluyéndolo.

\section{Implicancias metodológicas de la escritura situada}

En efecto, con base en lo propuesto por esta tendencia de la escritura situada, adscribible al grueso de propuestas filosóficas y científicas actuales de corte posestructuralista, ${ }^{4}$ cuyos presupuestos se

3 Lo es en la medida en que se adscribe a un discurso, el posmoderno, cuyo rasgo distintivo estriba en minar el optimismo atribuido por la Ilustración a los relatos de la Modernidad cuyas apuestas por el "determinismo, la racionalidad, la universalidad, la verdad, el progreso, la emancipación, la unidad, la continuidad, el ahorro [y] el mañana mejor" (Díaz, 2008, p.22) se ven conflictuadas por el reconocimiento que hace la posmodernidad de diversos planteamientos, entre otros, el carácter performativo del lenguaje.

4 "El posestructuralismo emerge dentro y en contra de la tradición modernista del estructuralismo [...], constituyéndose en una aproximación teórica al conocimiento y la sociedad que acoge la incertidumbre de los significados, el poder constitutivo del discurso y la efectividad política de la teoría y la investigación, [ofreciendo] una variedad de estrategias que cuestionan las ideas recibidas y las prácticas dominantes, haciendo visible su poder y creando espacios para que emerjan formas alternas de la práctica y el poder" (Gibson-Graham, 2002, pp.261-263). muestran, en menor o mayor grado, afines al deseo de desvirtuar las bases del sistema moderno de ciencia, autores como Feliu (2007) y Locke (1997) nos ofrecen una serie de valiosas consideraciones metodológicas que contribuyen a pensar, no solo el problema de la voz autorizada en la investigación social y su consecuente cariz epistémico, sino, además, el asunto atrás citado relativo al impacto de la escritura en la configuración de aquello que investiga el científico social, pues:

[...] en las ciencias sociales hay una larga tradición de inquietud por el impacto del observador/ científico sobre la sociedad bajo observación. Clásicamente, en su discurso, los científicos sociales han pretendido minimizar este efecto adoptando un tono objetivo e impersonal y anotando explícitamente, solo en ciertas formas estilizadas, los efectos incidentales de sus impactos en sus informadores. Ahora, sin embargo, algunos etnógrafos por lo menos, preocupados por la artificialidad de este procedimiento y sobre todo por su fracaso a la hora de abordar las realidades complejas de la interacción entre el observador y el observado, están repensando la naturaleza de sus textos y están experimentando con modos alternativos de presentación. (Locke, 1997, pp.20-21)

Estos modos, al desafiar la voz autorizada del sistema ciencia, ponen en jaque el marcado logocentrismo sobre el que esta se asienta, acercándonos de esta manera a una escritura que, si bien no ha podido prescindir de la responsabilidad que por antonomasia la ciencia le adjudica, se muestra precavida al respecto de tal demanda.

En ese orden de ideas, el primer aspecto del que nos habla Feliu tiene que ver con la necesidad de romper la distancia emocional, adentrándose en la vida misma de los informadores, participando de la etnografía en calidad de sujeto que, más que explicar lo que acontece, busca comprenderlo, de suerte que pueda sentir al otro "como parte de una misma cosa, que en el fondo reclama una implicación política" (2007, p.266). 
Tal vínculo logra, al acercar a los sujetos, poner en entredicho la lógica binaria sujeto (observador)/ objeto (observado), tan entrañable para la tradición occidental. Ahora, este acercamiento, que de entrada reta la lógica dualista, conlleva, por otra parte, la emergencia de una escritura conjunta, pues la lectura de realidad que se hace los involucra a todos, de manera que no habría una voz privilegiada llamada a representar lo que todos estarían en condiciones de decir, lo que favorecería a su vez una escritura polifónica, es decir, una escritura que todos tejen a partir de lo que cada quien aporta, reconociendo así el carácter dialógico de toda escritura, hecha a partir de voces individuales que no se subordinan a la hegemonía de una sola idea. Ni tampoco al peso de tener que decir siempre 'la verdad', como si en efecto existiese y fuese obligación de la escritura describirla, soslayando que el sentido nace con la escritura, elevándola a lenguaje.

De otra parte, en esa misma vía de querer ponderar una escritura al margen de la voz autorizada y de la tradición, el autor citado habla de una escritura que se explicita, es decir, se interroga respecto de sus fines a medida que se da, mostrándose vulnerable en el sentido de hacer evidentes sus extravíos, pues no existe un ideal al que deba, de antemano, llegar, motivo por el cual no hay qué restrinja su paso, no hay qué o quién la juzgue. Así pues, la naturaleza de estas consideraciones respecto de la escritura contribuye a la tarea de abrir un nuevo tipo de pensamiento que supere la primacía del logos y la presencia, permitiendo romper con el monopolio de la voz autorizada.

Evidentemente, lo expuesto hasta el momento se encuentra atravesado por una perspectiva epistemológica de carácter posmoderno que, al problematizar los principios fundantes de la teoría del conocimiento clásica, afectó también la forma en que venía conduciéndose la ciencia moderna, habituada como estaba a no poner en tela de juicio sus fundamentos. Logró que la ciencia, "tras una autorreflexión sobre su esencia, función y método, dudase abiertamente de sus supuestos: objetividad, neutralidad, universalidad, progresividad y predictibilidad" (Bermejo, 2008, p.12), lo que hizo plausible acceder finalmente a una nueva postura epistemológica de ciencia que no divorciara razón científica de sensibilidad, que no renunciase a incluir en su proceder componentes de orden estético, ético, político, pragmático, ideológico, social, cultural, histórico, etcétera, desvirtuados en el pasado por un determinismo cientificista hoy proscrito. Una nueva postura para la que:

[...] el fundamento de la realidad se desvela más blando, flexible y modelable de lo que se creía; la realidad no ofrece per se un fundamento estable e inmutable; el proceso de conocimiento es un proceso constructivo, no un proceso representativo o reproductivo de alguna supuesta naturaleza física y/o mental; el saber es algo puesto, no encontrado; la verdad es algo relativo a un marco racional de referencia y coherente con él, en el que adquiere su valor, y no correspondencia con una realidad independiente y ajena a toda interpretación previa; $y$, finalmente, la realidad es un complejo plural de versiones posibles de mundo, diferentes y legítimas, que no se deja reducir a sistema unitario. (Bermejo, 2008, p.13)

Es, pues, en este plano epistémico que resulta cómodo hablar ahora de la naturaleza constitutiva de la escritura en tanto escenario de creación.

\section{La escritura como instancia de creación: entre literatura y ciencia}

La relación ciencia y literatura se ha leído convencionalmente desde la dualidad. Su disyunción no solo ha sido alegórica del binarismo instaurado por Occidente entre razón y sensación, sino que ha sido además funcional al interés de la ciencia por hacer de su lenguaje, un lenguaje al servicio de "la verdad", es decir: objetivo, neutro, racional, certero, lógico, en oposición al de la literatura: subjetivo, intencional, metafórico, ambiguo, irracional, más afín a la fantasía. 
Ahora bien, el uso que se hace de cada uno de estos lenguajes suele estar en correspondencia con la función 'epistemológica' atribuida a su respectivo marco: así, mientras que con el lenguaje de la ciencia describimos el mundo como es, con el de la literatura nos lo inventamos como queremos. Sin embargo, cabe preguntar: ¿cuán lejos está el uno del otro?, ¿cuán distintos son? Dichas preguntas constituyen un importante punto de inflexión a partir del cual se hace necesario empezar a problematizar, no directamente la brecha entre literatura y ciencia, cosa que probablemente derive como efecto de lo que acontezca, sino el carácter representativo de la ciencia.

Se ha afirmado ya que la ciencia durante largo tiempo se preció de representar el mundo de forma fiel gracias a su fundamento objetivo, hasta que su pretensión se puso en entredicho en virtud de lo que la ciencia misma advirtió desde sus propios márgenes:

[...] la base empírica de la ciencia objetiva no tiene [...] nada de absoluto. La ciencia no descansa en una sólida roca. La estructura audaz de sus teorías se levanta, como si dijéramos, encima de un pantano. Es como un edificio construido sobre pilotes. Los pilotes son hincados desde arriba en el pantano, pero no en una base dada o natural; y si no hincamos los pilotes más profundamente no es porque hayamos alcanzado suelo firme. Simplemente paramos cuando nos satisface la firmeza de los pilotes, que es suficiente para soportar la estructura, al menos por el momento. (Popper, 1968, p.111 citado por Bermejo, 2008, p.51)

Como también en virtud de lo señalado por la filosofía actual que, a partir del triple giro epistémico, ${ }^{5}$ patenta una tesis que sirve de apoyo para la

5 Lingüístico, pragmático y estético cuyas tesis principales se traducen respectivamente en: "poner de relieve que no se da conocimiento sin lenguaje y, por tanto, ni racionalidad ni ciencia sin forma lingüística; prestar atención al carácter contextual, social y cultural de la realidad y del lenguaje, y, recuperar la centralidad de la creatividad en toda actividad humana, la metaforización como estrategia cognitiva básica y la pérdida de densidad ontológica de la realidad" (Bermejo, 2008, pp.52-53). desacralización de la ciencia en tanto instrumento de representación de un mundo-ahí-fuera:

[...] la realidad es siempre realidad descrita; lo que quiere decir que, por una parte, no existe una realidad ajena a la descripción y, por otra, que toda descripción es un modo de lenguaje. [...] No se puede hablar de realidad fuera de las interpretaciones, la realidad es siempre ya realidad interpretada y todo lo que se puede decir de la realidad son redescripciones, no representaciones de un supuesto mundo en sí, exterior y fijado en sus contenidos, que esperara a ser descubierto, al que hubiera que corresponder con reproducciones adecuadas y que pudiera ofrecer el criterio para determinar la exactitud de nuestras concepciones. La realidad no se encuentra, se construye. El contenido de la realidad es lingüístico, porque nuestro acceso a la realidad es lingüístico, nunca directo. (Goodman, 1978, citado por Bermejo, 2008, p.16)

En este orden de ideas, se concluye que la realidad no se constata, se crea a partir de las descripciones que de ella hacemos, lo que permitiría aseverar que lo que decimos acerca de la realidad nos es más próximo a nosotros que a la realidad misma:

Los juicios de realidad no dicen primeramente algo sobre las cosas, sino sobre nuestro modo de juzgarlas, es decir, sobre nuestra concepción del mundo. Wittgenstein convirtió en familiar para la filosofía y la ciencia la idea de que "mis juicios mismos caracterizan el modo de cómo juzgo, la esencia del juzgar", no la esencia del mundo. (Bermejo, 2008, p.35)

Ahora, estas descripciones mediante las cuales damos consistencia al mundo que creemos advertir están sujetas a un marco de referencia fuera del que no podríamos decir nada: "no hay mundo real que los científicos conozcan independientemente de las formulaciones lingüísticas, gráficas y matemáticas mediante las cuales los conciben" 
(Locke, 1997, p.51); habría, en consecuencia, tantos mundos como marcos de referencia posibles para constituirlos. De allí que la pregunta por un "mundo" o "mundos" en sí mismos es vacía. Solo existen modos-de-mundo o versiones que pueden considerarse mundos solo en ese sentido (Bermejo, 2008, p.17).

Esta perspectiva, en consecuencia, da lugar a un pluralismo del que antes se apartó la pretensión monopolista del físico para el que solo existía un único modo de descripción, "la física, que ejercería de única verdad para un mundo único y convertiría a los demás en falsos o irrelevantes" (Bermejo, 2008, p.18). Esta apertura a otras versiones alternativas de apreciar el mundo re-sitúa la ciencia en una posición análoga a otras formas de interpretación, arrebatándole el monopolio de la verdad.

La idea de verdad no es de hecho un criterio absoluto, sino relativo y subordinado. El científico, que dice dedicarse al descubrimiento de la verdad, somete en realidad el criterio de verdad a los parámetros de la teoría que construye y los datos de observación que trata a indicios significativos de generalizaciones a las que se adecuan. (Bermejo, 2008, p.34)

De este modo, la ciencia vendría a ser una "versión entre otras de mundo", incluida la literatura, cuyos criterios de validez no podrían enjuiciarse a partir de los estipulados por la ciencia, ya que "responden a objetivos con diferente interés e importancia" (Bermejo, 2008, p.34). Por supuesto, es claro que dicha perspectiva pluralista no busca arremeter contra la versión que posee la física del mundo, ${ }^{6}$ ni mucho menos subordinarla a otras versiones cuyos parámetros de apreciación, por el hecho de ser distintos a los de la versión señalada, no se podrían catalogar de poco rigurosos o exhaustivos, pues obedecen "a estándares diferentes

6 En tanto no se arroga el derecho a ponderar una versión sobre otra, así la de la física resulte de lo más reduccionista al afirmar que todo aquello que existe es exclusivamente físico. de los aplicados por la ciencia, lo que no los hace menos expeditos y adecuados para apreciar lo que se transmite en versiones perceptivas o pictóricas o literarias" (Bermejo, 2008, p.19).

A la base de este estallido de versiones respecto del mundo, o, como lo plantea el mismo Bermejo, versiones-mundo, estaría básicamente el supuesto de que "no hay un qué representado independiente del cómo se representa, como tampoco hay cosas-en-sí ni un mundo exterior ajeno a toda descripción", lo que nos lleva a pensar, en sintonía con Locke, que no hay más que signos de signos, puesto que, incluso aquella cosa que se dice representar es de por sí una representación, pues cosa "es ya una figura de ser, un modo de comportarse algo (opuesto, por ejemplo, a fantasma) construido por nuestra mente para explicarse aquella realidad primaria" (Ortega, 1997, p.46 citado por Bermejo, 2008, p.70). Por consiguiente, no hay bautizo de realidad que no acarree consigo o dé lugar simultáneamente a aquella realidad que nombra; por lo tanto, "la realidad se crea, no se encuentra ahí; los hechos se construyen activamente, no se reciben pasivamente" (Bermejo, 2008, p.22).

Esto supone consecuentemente que los textos producidos, tanto por los literatos como por los científicos, quienes por lo general consideraron "sus escritos como separados y distintos de su trabajo científico real" (Barthes, 1970, p.411 citado por Locke, 1997, p.31), son prácticamente constitutivos de sus 'mundos', y no mero reflejo, pues "el texto, en tanto tejido de códigos significantes, cumple una función constituyente. Aún más, los códigos del texto escriben al autor (y no a la inversa); los códigos crean el lector (y no a la inversa); en efecto, los códigos construyen el mundo que el texto pretende describir" (Locke, 1997, p.30).

Es posible refrendar a partir de la postura epistémica planteada, atribuida por Bermejo a Goodman (2008, p.20), la crisis a la que se ve abocada la metafísica de la representación, cuya idea de fundamento, revalidada además por la teoría del texto que advierte la insustancialidad de la escritura en tanto esta se exilia de un origen subjetivo al 
emerger, se desploma ante la afirmación de la pluralidad de mundos y de la inaccesibilidad a una realidad independiente de una descripción.

No se da, pues, ni una materia originaria, estrictamente independiente de su percepción, ni única. La materia se da en plural y se crea inseparable y al mismo tiempo que los mundos. Los muchos materiales de los que están hechos los mundos —materia, energía, ondas, fenómenos - se crean a la vez que esos mundos. Por eso la pregunta tradicional por el fundamento, entendida como búsqueda de una base sólida e inconmovible, garante de la verdad y la certeza del conocimiento, se desvanece. (Goodman, 1978, p.17 citado por Bermejo, 2008, p.20)

De esta manera, la búsqueda deviene en creación; lo esencial deja de residir fuera de la concepción que se torna fuerza creativa, capaz de insuflar vida, construir mundos, producir sentido. El acto de escribir el mundo, por lo tanto, se vuelve acto constitutivo en sí, siendo imposible de monopolizar dada la ausencia de un fundamento al que apelar. Ciencia, literatura, sentido común adquieren la potestad, en tanto versiones, de escribir el mundo sin subordinarse entre sí, sin arrogarse el derecho a decir la verdad, o a decirla siempre en relación con sus propios criterios de corrección y de éxito, lo que la vuelve local, situada, relativa. El ansia pretérita de afirmar lo que el mundo está siendo se aúna al deseo de discernir lo que puede llegar a ser, abocándonos así a la aventura de la invención cuyo riesgo radica en endilgarnos la responsabilidad de hacernos cargo de lo que hemos decidido 'ser' y de aquello que hemos contribuido a producir, incluyendo el paradigma mismo por el que ahora apostamos, el cual no pasa de ser también una mera "creación histórica particular, arbitraria, contingente" (Castoriadis, 1998, p.5).

Así pues, lo que para algunos resultaba talanquera: la ausencia de un fundamento, la carencia de una verdad, se vuelve oportunidad, lo que convierte la imposibilidad de saberlo todo, de contar con un saber absoluto, en posibilidad de transformación, restituyendo así al género humano la esperanza de auto-transformarse, al modificarse a sí mismo y al mundo que ha 'decidido', consciente o inconscientemente, crear. Por supuesto, dicha esperanza no es la de aspirar a que las cosas cambien en virtud de un designio divino o una ley natural, sino en razón de una "acción consciente y deliberada" (Poirier, 2006, p.56) liderada por los propios seres humanos.

Estas consideraciones filosóficas hacen, pues, manifiesta la condición poietica, constitutiva y autónoma del ser humano, que, ante la exhortación a crear, es decir, a escribir, se ve impelido a decidir sobre su propio futuro, en consonancia con el del colectivo del que forma parte. $Y$ es que decidir de modo 'autónomo' en este marco no es Ilanamente hacer lo que se me da la gana, escamoteando la incidencia de mi inconsciente o del deseo del Otro en mi decisión; es, de acuerdo con Castoriadis, precisamente evitar que mi inconsciente determine mis actos, estableciendo una relación reflexiva con mi imaginario, de manera que ya no me halle enajenado de él:

Así, la autonomía debe entenderse como algo que no remite a un estado acabado sino a una situación activa, que no remite a una persona ideal devenida Yo de una vez para siempre, la cual pronunciaría un discurso exclusivamente suyo y no generaría fantasías, sino a una persona real que no deja de adueñarse de lo ya adquirido, del discurso del Otro, que es capaz de develar sus fantasías como tales y no se deja dominar por ellas a menos que así lo desee. (Castoriadis, 1964, p.154 citado por Poirier, 2006, p.60)

Somos pues nosotros, en tanto seres humanos, los encargados de dar nombre a aquello que a su vez nos nombra, lo cual pone de relieve la importancia de identificarnos como auto-creación que se despliega como historia (Castoriadis, 2005, p.73). Condición que nos permite operar sobre las leyes, las normas, las reglas, las instituciones que a su vez operan sobre nosotros constituyéndonos 
de y en unas 'formas' singularísimas y particulares. En consecuencia, valdría la pena cuestionarnos al respecto de esas 'formas' que hemos creado para 'ser', hacer, pensar y, por supuesto, escribir en ciencias sociales, no con la intención de eliminarlas, pues bien sabemos que requerimos de ellas; más bien con el propósito de visibilizarlas y determinar, en función de nuestros deseos explícitos, su pertinencia y necesidad de transformación, sopesando simultáneamente la posibilidad, siempre a nuestro alcance, de producir sentido, es decir, de investigar.

\section{CONCLUSIONES}

El análisis señalado me permitió concluir, a lo largo del proceso, el peso que lo escrito posee en las visiones de mundo que concedemos a través de lo que publicamos como investigadores. En esa medida, me puso a pensar en la necesidad de considerar, al menos, tres importantes dimensiones a la hora de escribir sobre lo que hacemos en ciencias sociales: una dimensión estético-situada, referida al campo mismo de la creación y la performatividad lingüística; una dialógica, vinculada a la riqueza de sentidos que adquiere, en el marco de nuestras investigaciones, la palabra escrita en razón de su carácter polifónico y, por último, una ético-política, ligada a la capacidad de transformación instituida en el sujeto por la palabra viva que le nombra. Dimensiones cuya complejidad teórica simplifico ahora y expongo a través de una reflexión sobre lo que he dado en llamar: el carácter "situado" de la escritura en investigación social, tema respecto del cual versa puntualmente este artículo con el que busco, además, problematizar el paradigma moderno sobre el que se ha apoyado la investigación social en general, responsable de privilegiar, en materia de escritura, un discurso objetivista, representacional, racional, abstracto, libre de consideraciones valorativas (podríamos decir: de sujeto), en detrimento de un discurso práctico, local, singular, tendiente "a expresar el lenguaje de la acción y la actividad humanas" (Bolívar, 2002, p.20).

\section{RECONOCIMIENTOS}

Este artículo deriva del trabajo de grado que presenté como aspirante al título de magister en Estudios Sociales, en el marco de la línea: Literatura, Estudios Sociales e Investigación, de la Maestría en Estudios Sociales de la Universidad Pedagógica Nacional; maestría que cursé gracias a la beca que se me otorgó en virtud del Premio Nacional de Educación Francisca Radke a mejor trabajo de grado a nivel de especialización, que obtuve en el año 2008.

\section{REFERENCIAS}

Bajtín, M. (1986). Problemas de la poética de Dostoievski. México D. F.: Editorial Fondo de Cultura Económica.

Barthes, R. (1987). El susurro del lenguaje. Más allá de la palabra y la escritura. Madrid: Paidós.

Bermejo, D. (2008). La construcción de realidad. La realidad de la ficción y la ficción de la realidad. En D. Bermejo (Ed.). En las fronteras de la ciencia (11-49). Barcelona: Anthropos.

Bolívar, A. (2002). ¿De nobis ipsis silemus?: Epistemología de la investigación biográfico-narrativa en educación. Revista Electrónica de Investigación Educativa, 4(1), 1-26.

Castoriadis, C. (1998). Crítica a la racionalidad. Magazín Dominical, 781, 5, El Espectador.

Castoriadis, C. (2005). Los dominios del hombre: las encrucijadas del laberinto. Barcelona: Gedisa.

Derrida, J. (1989). La escritura y la diferencia. Barcelona: Siglo del Hombre.

Díaz, E. (2008). Posmodernidad. Caracas: Alfa.

Feliu, J. (2007). Nuevas formas literarias para las ciencias sociales: El caso de la autoetnografía. Athenea Digital, 12.

Gibson-Graham, J. (2002). El posestructuralismo. Revista Colombiana de Antropología, 38, 261-285.

Locke, D. (1997). La ciencia como escritura. Madrid: Frónesis, Cátedra Universitat de Valencia.

Poirier, N. (2006). Castoriadis. El imaginario radical. Buenos Aires: Ediciones Nueva Visión.

Ricour, P. (2002). Del texto a la acción. Ensayos de hermenéutica II. Buenos Aires: Fondo de Cultura Económica. 